\title{
Insetos fitófagos associados ao murici da praia, Byrsonima sericea (Malpighiaceae), na Restinga de Jurubatiba (RJ)
}

\author{
Vivian Flinte ${ }^{1}$, Cristina Oliveira Araujo ${ }^{1}$, Margarete Valverde de Macedo ${ }^{1}$ \& Ricardo Ferreira Monteiro ${ }^{1}$
}

'Laboratório de Ecologia de Insetos, Depto. de Ecologia, IB, UFRJ. Caixa Postal 68020, 21941-590 Rio de Janeiro-RJ, Brasil. flinte@ biologia.ufrj.br

\begin{abstract}
Phytophagous insects associated with Byrsonima sericea (Malpighiaceae) at Restinga de Jurubatiba (Rio de Janeiro State). This work aimed to investigate the composition, abundance and some behavioral aspects of phytophagous species associated with "murici da praia", Byrsonima sericea (Malpighiaceae), in the National Park of Restinga de Jurubatiba, Rio de Janeiro State, Brazil. During 14 months, from April 2003 to May 2004, bimonthly surveys were conducted on 120 plants, while observations on B. sericea insects were made since November 2000. An overall of 45 associated insect species were found, being 20 exophytic lepidopteran caterpillars, 17 exophytic Coleoptera, four leaf miners and four galling species. Lius sp. (Buprestidae), a leaf miner beetle, was the most abundant and frequent species, followed by the caterpillar Gonioterma indecora (Elachistidae). A comparison between lepidopteran caterpillars on $B$. sericea in the restinga and other Byrsonima species of the cerrado vegetation showed low insect similarities between these and B. sericea, which also had the lowest species richness. Both caterpillars and leaf miners abundance peaked between June and August, prior to the leaf flush, while the abundance of exophytic Coleoptera immatures increased simultaneously with leaf production. Possible explanations for the temporal distribution patterns of insects on $B$. sericea are discussed and a brief description of the ecological aspects is given for the main identified phytophagous insect species.
\end{abstract}

KEYWORDS. Gonioterma indecora; host record; insect-plant interactions; seasonality; species richness.

RESUMO. Insetos fitófagos associados ao murici da praia, Byrsonima sericea (Malpighiaceae), na Restinga de Jurubatiba (RJ). Este trabalho teve como objetivos descrever a composição de espécies de insetos fitófagos associados ao murici da praia, Byrsonima sericea (Malpighiaceae), no Parque Nacional da Restinga de Jurubatiba (RJ, Brasil) e estudar sua distribuição, sua abundância e alguns aspectos de seu comportamento. Durante 14 meses, de abril de 2003 a maio de 2004, foram vistoriadas bimestralmente 120 plantas, enquanto observações sobre a entomofauna associada a essa planta vêm sendo feitas desde novembro de 2000. Foram encontradas, ao todo, 45 espécies de insetos associadas, sendo 20 de lepidópteros exofíticos, 17 de coleópteros exofíticos, quatro de minadores e quatro de galhadores. Lius sp. (Buprestidae), um besouro minador de folhas, foi a espécie mais abundante e freqüente em $B$. sericea, seguido pela lagarta Gonioterma indecora (Elachistidae). A comparação entre as lagartas de Lepidoptera associadas a B. sericea na restinga com outras espécies de Byrsonima do cerrado mostrou uma baixa similaridade de insetos destas com B. sericea e uma menor riqueza nesta espécie. Tanto as lagartas de Lepidoptera como os minadores apresentaram seu pico de abundância entre os meses de junho e agosto, precedendo o pico de plantas com folhas novas, enquanto a abundância dos besouros exofíticos aumentou simultaneamente ao brotamento de folhas novas. São discutidas as possíveis causas para os padrões de distribuição temporal observados, bem como descrições de aspectos ecológicos das principais espécies identificadas associadas a B. sericea.

PALAVRAS-CHAVE. Gonioterma indecora; interação inseto-planta; planta hospedeira; riqueza de espécies; sazonalidade.

Inventários de insetos fitófagos realizados através da captura de adultos em armadilhas produzem rapidamente extensas listas de espécies, porém geram dados incompletos sobre a composição e a abundância das espécies em uma comunidade (Lewinsohn et al. 2001). Inventários de adultos e levantamentos de insetos imaturos em plantas hospedeiras são, desta forma, métodos complementares, que permitem a obtenção não apenas de uma lista de espécies, mas também do conhecimento de aspectos biológicos e de interações das espécies. Embora mais demorados, os inventários centrados em plantas hospedeiras permitem a identificação das plantasalimento, o estudo das distribuições temporal e espacial dos insetos, além de comparações das espécies associadas entre ecossistemas distintos, auxiliando até mesmo para o entendimento da evolução das interações inseto-planta.

Registros de plantas hospedeiras de insetos são escassos para a vasta maioria das espécies de insetos fitófagos no Brasil e são constituídos principalmente por espécies de interesse agrícola ou vetores de doenças, sendo o Quarto Catálogo de Silva e colaboradores (1968) uma das principais fontes. A partir da última década, estudos focados em diferentes grupos de insetos fitófagos e de suas plantas hospedeiras vêm revelando novos padrões para as comunidades tropicais. Trabalhos no cerrado brasileiro, por exemplo, mostram uma alta proporção de espécies de insetos oligófagos, ou seja, que se alimentam de gêneros de plantas hospedeiras dentro da mesma família, além de uma alta riqueza de espécies pouco abundantes (Diniz \& Morais 1995, 1997; Price et al. 1995; Marquis et al. 2002).

As restingas têm sofrido acelerada degradação causada pela expansão urbana no litoral, ameaçando sua biodiversidade única e pouco conhecida. Nas duas últimas décadas, muitos esforços têm sido feitos para estudar mais intensamente a fauna e a flora da restinga (Esteves 1998; Esteves \& Lacerda 2000; Rocha et al. 2004) e diversas espécies novas de insetos 
fitófagos têm sido descritas na restinga (e.g. Monteiro \& Becker 2002; Madeira et al. 2002; Maia 2001a). De uma maneira geral, estudos de flutuação populacional, biologia, ecologia e distribuição espacial de espécies de Coleoptera (especialmente da família Chrysomelidae), de Lepidoptera e de galhadores nas restingas do Rio de Janeiro, vêm demonstrando uma grande variedade de hábitos e uma considerável diversidade de padrões de ocorrência temporal (Macedo et al. 1994; Monteiro \& Macedo 2000; Ferraz \& Monteiro 2003; Gonçalves \& Macedo 2003; Flinte \& Macedo 2003; Flinte \& Macedo 2004; Grenha et al. 2004; Macedo et al. 2004; Monteiro et al. 2004a, b).

Porém, mesmo considerando-se as espécies de plantas mais abundantes na restinga, pouco se conhece sobre os insetos a elas associados. Esse, por exemplo, é o caso de Byrsonima sericea DC. (Malpighiaceae), uma planta muito comum nas restingas do Estado do Rio de Janeiro, mas que, exceto por descrições de suas galhas (Maia 2001a, b), pouco se sabe sobre sua entomofauna associada. Um estudo com três espécies de Byrsonima no cerrado revelou uma riqueza média de 26 espécies de lagartas de Lepidoptera por espécie de planta e constatou que, apesar da riqueza ter sido semelhante entre as três espécies $(25,25$ e 28 espécies de lagartas), a similaridade na composição de espécies não foi alta, variando de 0,22 a 0,46 (Diniz \& Morais 1997). No presente trabalho, é apresentada a composição de espécies de insetos fitófagos associados a $B$. sericea na Restinga de Jurubatiba, RJ, são descritos alguns aspectos da ecologia e do comportamento das espécies encontradas e os resultados são comparados com estudos similares feitos principalmente no cerrado.

\section{MATERIALE MÉTODOS}

Área de estudo. O estudo foi realizado no Parque Nacional da Restinga de Jurubatiba (PNRJ) (Fig. 1; S 22 ${ }^{\circ} 16^{\prime}$ e W 40³9'), que abrange os municípios de Macaé, Carapebus e Quissamã, no Estado do Rio de Janeiro (Brasil). Com uma área total de 14.860 ha, o Parque apresenta dez formações vegetais com diferentes fitofisionomias, desde comunidades com porte herbáceo a arbustivo arbóreo, em ambientes mais secos a periodica ou permanentemente úmidos (Araujo et al. 1998). Indivíduos de $B$. sericea foram vistoriados nas quatro formações vegetais, nas quais a espécie comumente ocorre: arbustiva aberta de Clusia, arbustiva aberta de Ericaceae, mata periodicamente inundada e mata de cordão arenoso (Araujo et al. 1998), todas localizadas próximas às lagoas Comprida e de Cabiúnas (ver Araujo et al. 1998 para uma descrição detalhada das formações vegetais).

O PNRJ apresenta um verão tipicamente quente e chuvoso (temperatura média de $28^{\circ} \mathrm{C}$ e $91,9 \mathrm{~mm}$ de precipitação média mensal) e um inverno com temperaturas mais amenas e precipitação mais reduzida (temperatura média de $24^{\circ} \mathrm{C}$ e 48,8 mm de precipitação média mensal) (dados de 1997 a 2004 fornecidos pela Estação Evaporimétrica Agropecuária Carapebus Ltda.). Apesar deste padrão geral, observam-se

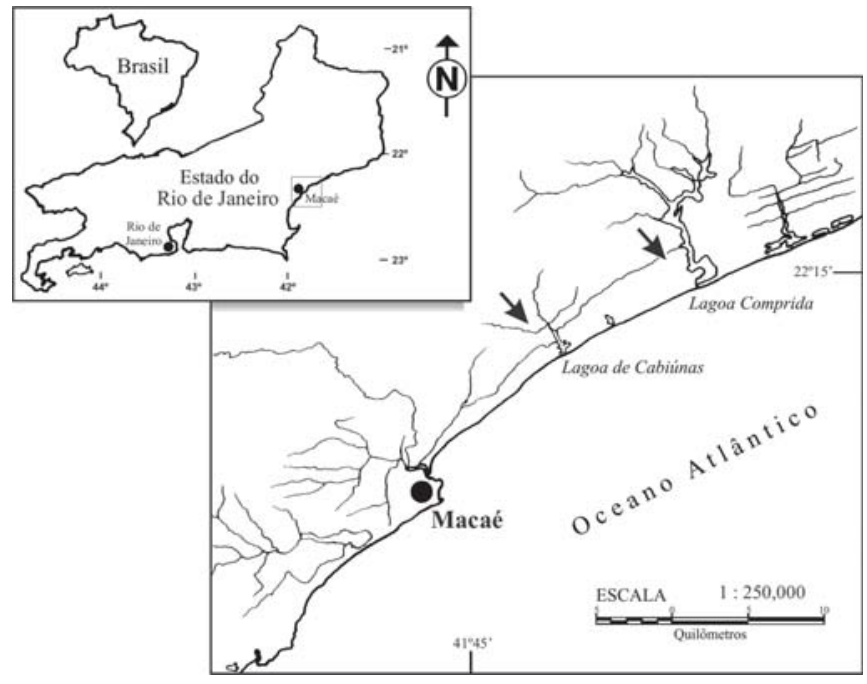

Fig. 1. Mapa mostrando a localização das áreas de estudo (setas) no PNRJ, Estado do Rio de Janeiro.

variações, especialmente em relação ao volume de precipitação, de um ano para o outro, como o maior volume de chuvas no verão de 2004 em relação ao de 2003 e ao de 2002 (Fig. 2).

Planta hospedeira. Byrsonima sericea, o murici da praia, é uma arvoreta com cerca de $2,5 \mathrm{~m}$ de altura, cujas folhas são verdes e glabras na face adaxial e pilosas e douradas na face abaxial. Sua distribuição geográfica no Brasil vai desde o estado do Paraná até o Ceará, em floresta pluvial atlântica montana e restinga. É uma das plantas dominantes nas restingas fluminenses, ocorrendo nas principais comunidades vegetais do PNRJ, tais como as formações de moitas abertas de Clusia e de Ericaceae, além da mata de restinga e da mata paludosa (Araujo et al. 2001).

Amostragem e tratamento dos dados. Durante 14 meses, entre abril de 2003 e maio de 2004, 120 plantas marcadas (30 em cada área), aleatoriamente escolhidas, foram vistoriadas bimestralmente, procurando-se exaustivamente quatro grupos de insetos fitófagos: Lepidoptera (apenas lagartas exofíticas), Coleoptera exofíticos (imaturos e adultos), minadores e galhadores. Entretanto, algumas coletas avulsas da entomofauna associada a $B$. sericea começaram em novembro de 2000, apenas na área de mata de cordão arenoso. Todos os grupos de insetos tiveram seus indivíduos contados em cada planta vistoriada, exceto as galhas, para as quais era registrado, apenas, cada tipo presente na planta. Na contagem das minas foram consideradas apenas aquelas sem orifício de saída do adulto ou de parasitóides.

No campo, todas as espécies de insetos eram observadas quanto ao seu comportamento, ao modo de alimentação e aos hábitos (por ex.: construção de abrigos), bem como a condição fenológica de cada planta. Espécies de insetos registradas pela primeira vez eram coletadas e levadas para criação em laboratório, para posterior identificação. Por meio da criação distinguiram-se também os insetos "turistas" (aqueles que 
não se alimentam da planta) dos verdadeiramente associados à planta. Em laboratório eram também efetuadas observações referentes à biologia e à ecologia de cada espécie de imaturo criada.

Para a descrição dos padrões de abundância e distribuição temporal dos insetos foram consideradas, apenas, aquelas espécies que apresentaram imaturos alimentando-se de $B$. sericea. Para 12 das 17 espécies de Coleoptera exofíticos, ou seja, exceto para as espécies da subfamília Chlamisinae, foram encontrados somente os adultos alimentando-se na planta; estes casos foram incluídos na lista de espécies, mas não computados nas demais análises quantitativas.

É possível que a abundância de alguns grupos de insetos esteja superestimada em relação a outros, devido ao tempo de desenvolvimento superior a dois meses em algumas espécies, o que pode ter levado a uma recontagem de indivíduos durante as vistorias bimensais. Para obtenção da riqueza estimada de espécies foi utilizado o estimador Jack-Knife 1, através do programa Biodiversity Pro (como em Battirola et al. 2005). Para os cálculos de similaridade entre a composição de espécies de $B$. sericea na restinga e outras três espécies de Brysonima no cerrado foi usado o Coeficiente de Sorensen segundo Krebs (1989). Para testar se a distribuição das lagartas de lepidópteros durante a época de pouca disponibilidade de folhas novas era ao acaso nos indivíduos de B. sericea, ou se elas estavam concentradas nas poucas plantas com tal recurso, foi feito um teste de Qui-quadrado.

Todos os insetos coletados como adultos ou criados a partir de larvas foram depositados na coleção do Laboratório de Ecologia de Insetos no Instituto de Biologia/UFRJ, no Museu de Zoologia/USP (Curculionidae) ou na coleção do Dr. Vitor Becker (microlepidópteros).

\section{RESULTADOS EDISCUSSÃO}

Composição e riqueza de espécies. Considerando-se o período total de observações, de novembro de 2000 a maio de 2004, foram encontradas 45 espécies de insetos (larvas ou adultos) alimentando-se de $B$. sericea no PNRJ, sendo 20 de lepidópteros exofíticos, 17 de coleópteros exofíticos, quatro de minadores e quatro de galhadores (Tabela I). Obteve-se o registro fotográfico de todas as espécies de insetos endofíticos associadas a $B$. sericea, das espécies mais abundantes de exofíticos e também de algumas pouco abundantes (Fig. 3). Em 840 vistorias-plantas ao longo do período de amostragem de 14 meses, foi encontrado um total de 8.462 indivíduos imaturos, pertencentes a 23 espécies, de Lepidoptera e Coleoptera exofíticos e de minadores. A curva de acumulação de espécies com o aumento do número de plantas vistoriadas indica uma tendência à estabilização dessa riqueza e, através do estimador Jack-Knife 1, estimou-se que $82,1 \%$ da riqueza de espécies associadas foi amostrada em nosso estudo, sugerindo que a composição e riqueza de espécies obtidas é bem representativa de toda entomofauna associada a essa planta (Fig. 4).

Em um trabalho de quatro anos no cerrado brasileiro, Diniz

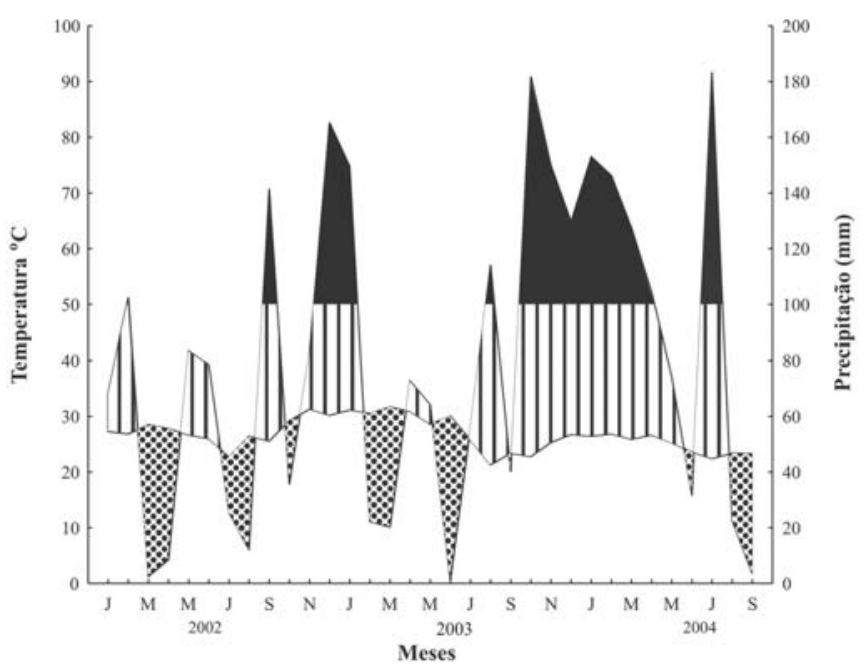

Fig. 2. Diagrama climático da área de estudo de janeiro de 2002 a setembro de 2004. Dados fornecidos pela Estação Evaporimétrica Agropecuária Carapebus Ltda. Área pontilhada = período seco; área hachurada $=$ período úmido; área cheia $=$ período superúmido .

e Morais (1997) encontraram 53 espécies de lagartas de lepidópteros associadas a três espécies de Byrsonima: $B$. crassa, B. coccolobifolia e $B$. verbascifolia, com 25,28 e 25 espécies, respectivamente. Assim, observa-se que as espécies de Byrsonima no cerrado apresentam riqueza de lagartas mais elevada do que na restinga do PNRJ (20 espécies, sendo 17 em 14 meses de coletas sistemáticas e mais três em coletas avulsas feitas antes do período principal de amostragem). Entretanto, o presente estudo na restinga teve a área amostrada (2 ha) bem menor do que no cerrado (cerca de 6 ha). Portanto, tal diferença na riqueza de espécies poderia ser creditada, em parte, a esse esforço diferenciado de amostragem.

A similaridade na composição de espécies de lagartas de Lepidoptera de $B$. sericea na restinga com $B$. crassa, $B$. coccolobifolia e $B$. verbascifolia do cerrado de Brasília foi de $0,26,0,17$ e 0,13 , nesta ordem. Nota-se que estes valores de similaridade tendem a ser mais baixos do que os encontrados entre essas três espécies no cerrado (ver Diniz \& Morais 1997), com exceção do valor entre $B$. sericea e $B$. crassa, que foi superior à menor similaridade entre as espécies do cerrado $(0,22)$. Cabe ressaltar que $B$. crassa também teve os maiores valores de similaridade com as outras duas espécies de Byrsonima no cerrado. Uma baixa similaridade na composição de lagartas exofíticas, de 0,16 , também foi encontrada entre $B$. sericea na restinga e $B$. crassifolia na Costa Rica, que teve uma riqueza de 17 espécies (Guadamuz et al. 1998). A explicação para os valores mais baixos de similaridade entre $B$. sericea $\mathrm{e}$ as espécies de Byrsonima em outros biomas pode estar relacionada com a distância e a heterogeneidade ambiental entre as localidades estudadas. Apesar da baixa similaridade observada entre as espécies de Byrsonima, notou-se que alguns gêneros de Lepidoptera apresentam uma forte interação com Byrsonima, como é o caso de Gonioterma, Euphaneta e Bardaxima. Esses gêneros apresentam espécies ocorrendo 
Tabela I. Lista de espécies associadas a Byrsonima sericea, mostrando os recursos que cada espécie utiliza da planta hospedeira, a fase em que os indivíduos foram coletados e o tipo de proteção usado pelos imaturos. $\mathrm{L}=$ larva; $\mathrm{A}=$ adulto.

\begin{tabular}{|c|c|c|c|}
\hline Espécies & Recurso alimentar & Fase coletada & Proteção dos imaturos \\
\hline \multicolumn{4}{|l|}{ LEPIDOPTERA } \\
\hline Arctiidae & & & \\
\hline Rhipha strigosa (Walker, 1854) & Folha & $\mathrm{L}$ & - \\
\hline Dalceridae & & & \\
\hline Acraga ochracea (Walker, 1855) & Folha & $\mathrm{L}$ & - \\
\hline Elachistidae & & & \\
\hline Antaeotricha deltopis (Meyerick, 1915) & Folha & $\mathrm{L}$ & Junta duas folhas verdes \\
\hline Gonioterma exquisita (Duckworth, 1964) & Folha & $\mathrm{L}$ & Casulo fezes + seda \\
\hline Gonioterma indecora (Zeller, 1854) & Folha & $\mathrm{L}$ & Casulo fezes + folhas \\
\hline Stenoma prope ascodes (Meyerick, 1915) & Folha & $\mathrm{L}$ & Junta duas folhas verdes \\
\hline Gelechiidae & & & \\
\hline $\begin{array}{l}\text { Commatica sp. } \\
\text { Hesperiidae }\end{array}$ & Meristema caule & $\mathrm{L}$ & Interior do meristema \\
\hline $\begin{array}{l}\text { Elbella intersecta rufitegula Mielke, } 1994 \\
\text { Limacodidae }\end{array}$ & Folha & $\mathrm{L}$ & Dobra pedaço de folha \\
\hline $\begin{array}{l}\text { Phobetron hipparchia (Cramer, 1777) } \\
\text { Lycaenidae }\end{array}$ & Folha & $\mathrm{L}$ & - \\
\hline $\begin{array}{l}\text { Kolana ergina (Hewitson, 1867) } \\
\text { Megalopygidae }\end{array}$ & Folha & $\mathrm{L}$ & - \\
\hline $\begin{array}{l}\text { Megalopyge lanata (Stoll-Cramer, 1780) } \\
\text { Mimallonidae }\end{array}$ & Folha & $\mathrm{L}$ & Pêlos urticantes \\
\hline $\begin{array}{l}\text { Euphaneta divisa (Walker, 1855) } \\
\text { Noctuidae }\end{array}$ & Folha & $\mathrm{L}$ & Casulo rígido de folhas \\
\hline $\begin{array}{l}\text { Concana mundissima (Walker, 1858) } \\
\text { Notodontidae }\end{array}$ & Folha & $\mathrm{L}$ & - \\
\hline $\begin{array}{l}\text { Bardaxima donatia (Shaus, 1928) } \\
\text { Oecophoridae }\end{array}$ & Folha & $\mathrm{L}$ & - \\
\hline $\begin{array}{l}\text { Inga inflammata (Meyerick, 1916) } \\
\text { Psychidae }\end{array}$ & Folha & $\mathrm{L}$ & Folhas secas \\
\hline Lumacra sp. & Folha & $\mathrm{L}$ & Casulo folhas + seda \\
\hline Oiketicus kirbyi Guilding, 1827 & Folha & $\mathrm{L}$ & Casulo gravetos + seda \\
\hline Psychidae sp. & Flor / Folha & $\mathrm{L}$ & Casulo folhas, flores + seda \\
\hline Pyralidae & & & \\
\hline Carthara abrupta (Zeller, 1881) & Folha & $\mathrm{L}$ & Hábito gregário + seda \\
\hline Sarasota sp. & Flor & $\mathrm{L}$ & Seda \\
\hline
\end{tabular}

\section{COLEOPTERA}

Chrysomelidae

Alticinae sp. 1

Chlamisus sp. 1

Chlamisus sp. 2

Chlamisus sp. 3

Chlamisus sp. 4

Chrysomelidae sp. 1

Chrysomelidae sp. 2

Fulcidax monstrosa (Fabricius, 1798)

Lamprosoma triste Guérin-Méneville, 1844

Curculionidae

Chalcoldermus sp.

Naupactus lar Germar, 1824

Naupactus sp.

Pantomorus sp.

Piazorhinus sp.

Plectophoroides sp.

Hispinae

Octhispa gemmata Germar, 1824

Scarabaeidae

Rutela lineola (Linnaeus, 1767)
Folha jovem

Folha jovem / Caule

Folha jovem / Caule

Folha jovem / Caule

Folha jovem / Caule

Folha

Folha

Caule

Folha jovem

Folha jovem

Folha

Folha

Folha

Folha jovem

Folha

Folha jovem

Flor
Casulo fezes

Casulo fezes

Casulo fezes

Casulo fezes

Casulo fezes

Casulo fezes
A

A

A

A

A

A

A

A

A

A 
Tabela I. Continuação.

\begin{tabular}{|c|c|c|c|}
\hline Espécies & Recurso alimentar & Fase coletada & Proteção dos imaturos \\
\hline \multicolumn{4}{|l|}{ MINADORES } \\
\hline \multicolumn{4}{|l|}{ Buprestidae } \\
\hline Pachyschelus sp. & Folha & $\mathrm{L}$ & Endofagia \\
\hline Lius sp. & Folha & $\mathrm{L}$ & Endofagia \\
\hline \multicolumn{4}{|l|}{ Lepidoptera } \\
\hline Lepidoptera não identificado & Folha & $\mathrm{L}$ & Endofagia \\
\hline \multicolumn{4}{|l|}{ Outros } \\
\hline Minador não identificado & Folha & $\mathrm{L}$ & Endofagia \\
\hline \multicolumn{4}{|l|}{ GALHADORES } \\
\hline \multicolumn{4}{|l|}{ Cecidomyiidae } \\
\hline Bruggmaniella byrsonimae (Maia et al., 1992) & Botão & $\mathrm{L}$ & Endofagia \\
\hline Oligotrophini sp. & Folha & $\mathrm{L}$ & Endofagia \\
\hline Cecidomyiinae sp. & Caule & $\mathrm{L}$ & Endofagia \\
\hline \multicolumn{4}{|l|}{ Lepidoptera } \\
\hline Lepidoptera não identificado & $\begin{array}{l}\text { Caule, pecíolo, botão, } \\
\text { nervura folha, pedúnculo } \\
\text { floral }\end{array}$ & $\mathrm{L}$ & Endofagia \\
\hline
\end{tabular}

em todas ou em quase todas as espécies de plantas citadas, o que pode indicar uma história evolutiva mais estreita desses insetos com Byrsonima.

As espécies de Coleoptera exofíticos mais comuns em $B$. sericea foram Fulcidax monstrosa (Chrysomelidae) e Chlamisus spp. (Chrysomelidae) e as de minadores foram Lius sp. e Pachyschelus sp. (Buprestidae). Já em relação aos Lepidoptera exofíticos, Gonioterma indecora, G. exquisita (Elachistidae), Euphaneta divisa (Mimallonidae), Inga inflammata (Oecophoridae) e Carthara abrupta (Pyralidae) foram, em ordem decrescente, as espécies mais comuns. Dessas cinco espécies na restinga, três (E. divisa, G. exquisita e $G$. indecora) também estão entre as sete espécies de lepidópteros mais abundantes em Byrsonima no cerrado de Brasília (Diniz \& Morais 1997).

Os minadores foram os insetos que tiveram maior abundância em $B$. sericea, seguidos pelos lepidópteros exofíticos e, por fim, pelos besouros exofíticos (Tabela II). Dentre os quatro tipos de minas encontrados, a mina expandida, mais abundante, produzida por Lius sp., foi cerca de três vezes mais abundante que a mina linear de Pachyschelus sp., segunda em abundância.

Foram encontradas quatro espécies de galhadores, sendo três de Cecidomyiidae (Diptera) e uma de Lepidoptera. Esta última espécie induz galhas esferóides no caule, no botão floral, no pecíolo da folha, na nervura da folha ou ainda no pedúnculo floral. Em relação às espécies de dípteros galhadores, Cecidomyiinae sp. induz uma grande galha esférica no caule, Bruggmaniella byrsonimae induz uma galha marrom no botão floral e Oligotrophini sp. induz uma galha epidérmica nas folhas (Fig. 3Q-T).

Em cada um dos três grupos estudados, uma espécie destacou-se por sua abundância em relação às demais: $G$. indecora (Lepidoptera exofítico), F. monstrosa (Coleoptera exofítico) e Lius sp. (Coleoptera minador) (Tabela II). O minador Lius sp. foi a espécie mais freqüente nas plantas, pois cerca de $75 \%$ das plantas vistoriadas apresentavam pelo menos um indivíduo desta espécie. No que diz respeito às lagartas exofíticas, $G$. indecora esteve presente em $48 \%$ das plantas amostradas, o que é quase cinco vezes mais freqüente do que E. divisa, segunda espécie de lagarta mais freqüente. Considerando-se apenas os imaturos de besouros exofíticos, F. monstrosa foi a espécie mais freqüente nas plantas, sendo encontrada em $23 \%$ das plantas vistoriadas (Tabela II).

Biologia e ecologia das principais espécies associadas a Byrsonima sericea. Existem poucos dados disponíveis na literatura sobre a biologia e a ecologia da grande maioria das espécies encontradas em $B$. sericea. As observações em campo e no laboratório mostraram que os imaturos de $70 \%$ das espécies de lepidópteros exofíticos constroem algum tipo de abrigo ou proteção (feitos normalmente com folhas, combinadas muitas vezes com fezes e/ou seda), o que também é bem comum nas principais espécies de Coleoptera exofíticos encontradas (casulos normalmente confeccionados com fezes) (Tabela I).

Em um cerrado próximo a Brasília, Diniz \& Morais (1997) encontraram que $65 \%$ das lagartas exofíticas folívoras constroem algum tipo de abrigo, que, em geral, da mesma forma que na restinga, é uma combinação de diversos materiais como seda, excrementos e diversas partes da planta, onde empupam mais tarde. Trabalhos sugerem que os abrigos das lagartas exofíticas, além da proteção contra dessecação (Diniz et al. 2000), fornecem também proteção contra inimigos naturais, embora sejam poucos os que demonstram isso experimentalmente (e.g. Jones et al. 2002). Em Chyrsomelidae, por exemplo, alguns estudos já demonstraram que o casulo de fezes das larvas proporciona proteção contra predadores, 

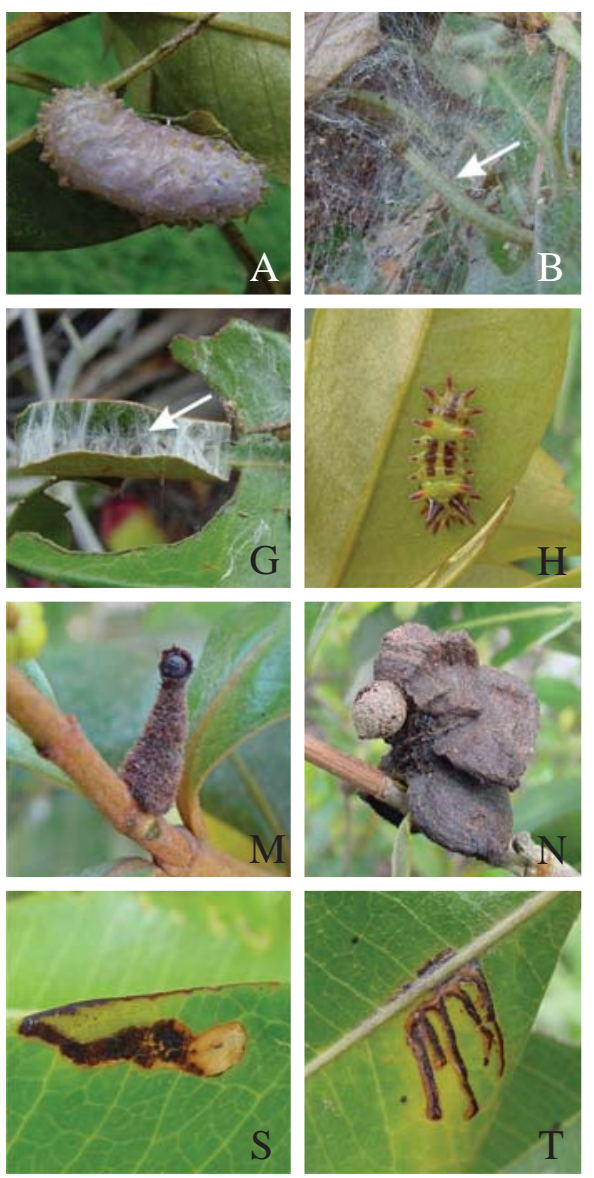
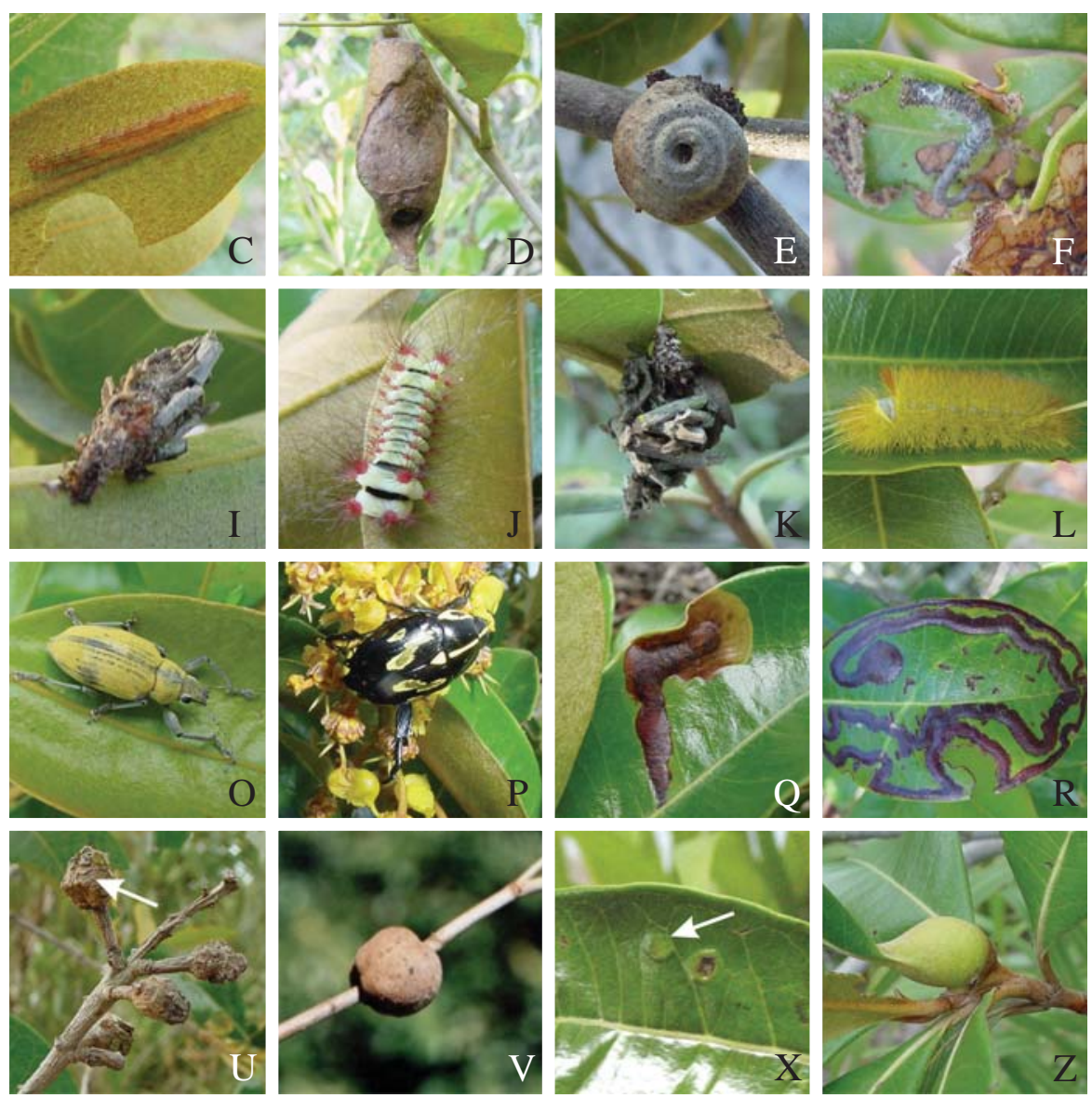

Fig. 3. Algumas espécies de insetos fitófagos associados a Byrsonima sericea no PNRJ. Os aspectos ecológicos de cada uma das espécies identificadas estão descritos no texto. Lagartas de Lepidoptera exofíticas: Acraga ochracea (A), Carthara abrupta (B), Concana mundissima (C), Euphaneta divisa (D), Gonioterma exquisita (E), Gonioterma indecora (F), Inga inflammata (G), Kolana ergina (H), Lumacra sp. (I), Megalopyge lanata (J), Oiketicus kirbyi (K) e Ripha strigosa (L). Coleópteros exofíticos: larva de Chlamisus sp. (M), larva de Fulcidax monstrosa (N), Naupactus lar (O) e Rutela lineola (P). Minadores: Lius sp. (Q), Pachyschelus sp. (R), espécie de Lepidoptera não identificada (S) e minador não identificado (T). Galhadores: Bruggmaniella byrsonimae (U), Cecidomyiinae sp. (V), Oligotrophini sp. (X) e espécie de Lepidoptera não identificada $(\mathrm{Z})$.

principalmente formigas e hemípteros, e também parasitóides (Wallace 1970; Jolivet 1997; Nogueira-de-Sá \& Trigo 2002; Flinte \& Macedo 2004). As condições de alta radiação solar, ventos freqüentes e solo arenoso, presentes na restinga, sugere que os abrigos podem estar funcionando, em parte, como proteção contra dessecação.

Seguem alguns comentários descritivos sobre o comportamento e a ecologia da maioria das espécies de imaturos observadas em $B$. sericea e dados complementares oriundos da literatura.

\section{Lepidoptera exofíticos}

\section{Acraga ochracea (Lepidoptera: Dalceridae)}

Conhecida vulgarmente como "lagarta gelatinosa", apresenta aspecto gelatinoso e tubérculos carnudos no corpo, além de uma coloração rósea (Fig. 3A), e deixa uma marca de muco ao deslizar sobre a superfície das folhas. A única lagarta foi encontrada no mês de outubro alimentando-se de folhas.
Há registro dessa mesma espécie em plantas da família Erythroxylaceae (Diniz \& Morais 1995) e Arecidae (Cisneros 1995).

Antaeotricha deltopis (Lepidoptera: Elachistidae)

Essa lagarta de microlepidóptero possui listras longitudinais pretas e brancas e permanece abrigada entre duas folhas, que junta através de seda, e que também lhe servem de alimento até a fase pupal. Joga-se rapidamente ao chão quando molestada. Ocorreu em baixa abundância ao longo de todo o ano, com um discreto pico de indivíduos em maio.

\section{Bardaxima donatia (Lepidoptera: Notodontidae)}

A lagarta alimenta-se de maneira exposta nas folhas, normalmente na face inferior, e possui coloração avermelhada no dorso, com as laterais do corpo amarelas, e um fino prolongamento amarelo no final do abdômen. Foram encontrados cerca de 15 indivíduos desta espécie, com predomínio nos meses de junho e fevereiro. Há registros de 
sua ocorrência em B. coccolobifolia e B. crassa no cerrado (Diniz \& Morais 1997). Bardaxima lucilinea foi registrada em B. crassifolia na Costa Rica (Nielsen et al. 2004), o que parece reforçar a associação deste gênero de lagartas com Byrsonima ou espécies aparentadas.

\section{Carthara abrupta (Lepidoptera: Pyralidae)}

É a única espécie encontrada, cujas lagartas apresentam hábito gregário, formando grupos de aproximadamente seis indivíduos em um emaranhado de folhas, seda e fezes, que serve de abrigo (Fig. 3B). Alimentam-se das folhas deste emaranhado até estas se esgotarem e, então, constroem outro abrigo, onde posteriormente empupam. Quando jovens, são finas e longas, e apresentam coloração esverdeada e, quando maduras, adquirem coloração marrom. Apresentaram uma distribuição esparsa ao longo do ano. É uma espécie generalista uma vez que, no cerrado, há registros de sua alimentação em plantas de diferentes famílias (Morais com. pess.).

\section{Concana mundissima (Lepidoptera: Noctuidae)}

$\mathrm{Na}$ literatura são citados alguns sinônimos tais como Concana splendens (Möschler), Concana hoshea (Druce) e Concana mundula Dognin. A lagarta é fina e alongada; quando jovem possui coloração avermelhada e, mais madura, amareloesverdeada (Fig. 3C). O corpo é recoberto por pêlos curtos e esparsos. O único indivíduo foi encontrado em dezembro alimentando-se externamente de folhas. Diniz e Morais (1997) registraram esta mesma espécie em $B$. coccolobifolia.

\section{Elbella intersecta rufitegula (Lepidoptera: Hesperiidae)}

As lagartas desse hesperídeo frequientemente cortam e dobram parte da folha para se abrigar, formando um envelope típico das larvas dessa família. Além de muitos pêlos esbranquiçados, as lagartas possuem listras pretas e amarelas ao longo do corpo, sendo a cabeça e o final do abdômen de cor vermelha. Sai do abrigo apenas para se alimentar de folhas próximas e troca de abrigo várias vezes à medida que cresce. Foram encontrados apenas alguns indivíduos distribuídos em estações distintas. Trata-se de uma espécie polífaga no cerrado (Morais com. pess.).

\section{Euphaneta divisa (Lepidoptera: Mimallonidae)}

A lagarta constrói um rígido casulo a partir de folhas, que permanece aberto nas extremidades superior e inferior (Fig. 3D). Apresenta finos prolongamentos na cabeça, e o formato do final de seu abdômen fecha uma das extremidades do casulo. De início o casulo é relativamente maleável, mas posteriormente se torna bastante rígido. O casulo fica preso ao ramo através de resistentes fios de seda, com os quais a lagarta também aproxima folhas para sua alimentação. A lagarta empupa dentro do casulo, cujas extremidades permanecem abertas. Ocorre o ano inteiro, predominantemente no outono e no inverno. Foi encontrada também em $B$. crassa e $B$. verbascifolia no cerrado (Diniz \& Morais 1995).
Tabela II. Abundâncias absoluta e relativa dentro de cada grupo das espécies de imaturos mais comuns de Lepidoptera exofíticos $(n=17)$ e das espécies de Coleoptera exofíticos $(n=5)$ e de minadores $(n=4)$, e freqüência de cada espécie nas plantas (incluindo os galhadores).

\begin{tabular}{lccc}
\hline & $\begin{array}{c}\text { Abundância } \\
\text { absoluta }\end{array}$ & $\begin{array}{c}\text { Abundância } \\
\text { relativa (\%) }\end{array}$ & $\begin{array}{c}\text { Freqüência } \\
(\%)\end{array}$ \\
\hline \multicolumn{1}{c}{ LEPIDOPTERA } & 3.157 & & \\
Gonioterma indecora & 2.603 & 82,5 & 47,5 \\
Inga inflammata & 157 & 5,0 & 10,7 \\
Gonioterma exquisita & 133 & 4,2 & 8,6 \\
Euphaneta divisa & 120 & 3,8 & 10,8 \\
Carthara abrupta & 59 & 1,9 & 1,0 \\
Outros & 85 & 2,7 & - \\
\multicolumn{1}{c}{ COLEOPTERA } & 989 & & \\
Fulcidax monstrosa & 847 & 85,6 & 23,3 \\
Chlamisus spp. & 142 & 14,4 & 12,9 \\
$\quad$ & & & \\
$\quad$ MINADORES & 4.314 & & \\
Lius sp. & 2.941 & 68,2 & 75,2 \\
Pachyschelus sp. & 1.041 & 24,1 & 41,4 \\
Minador não identificado & 261 & 6,1 & 14,7 \\
Lepidoptera não identificado & 71 & 1,6 & 5,9 \\
$\quad$ & & & \\
$\quad$ GALHADORES & - & - & 59,6 \\
Lepidoptera não identificado & - & - & 3,1 \\
Bruggmanniella byrsonimae & - & - & 0,2 \\
Oligotrophini sp. & - & - & \\
Cecidomyiinae sp. & - & - & \\
\hline
\end{tabular}

Gonioterma exquisita (Lepidoptera: Elachistidae)

O casulo desta lagarta é um dos mais incomuns da ordem, assemelhando-se à concha de um caracol (Fig. 3E). Este casulo é feito com a própria seda da lagarta e com tricomas da planta, como descrito por Diniz e colaboradores (2000). No início de seu desenvolvimento, a lagarta começa construindo seu casulo abrigada entre duas folhas, que permanecem unidas por uma camada de seda. Ela costuma se alimentar na parte inferior de suas folhas, deixando marcas mais ou menos circulares e, mais tarde, empupa dentro de seu próprio casulo. Ocorre ao longo de todo ano, embora seja um pouco mais abundante no outono. No cerrado, a espécie foi encontrada em $B$. crassa e $B$. verbascifolia (Diniz \& Morais 1997).

\section{Gonioterma indecora (Lepidoptera: Elachistidae)}

A lagarta, quando ainda muito jovem, permanece dentro de um abrigo de seda construído entre duas folhas, até conseguir construir um casulo de fezes em forma de cone ao redor de seu corpo (Fig. 3F). Quando o casulo já está um pouco maior, o abrigo de seda se rompe e as folhas se separam. A lagarta, então, dentro de seu casulo, junta um emaranhado de folhas para perto de si, que lhe serve de alimento e abrigo. Quando perturbada, a lagarta regurgita um líquido escuro e/ ou se joga ao chão com movimentos bruscos. No final de seu desenvolvimento, a lagarta constrói uma câmara de fezes e seda na entrada do cone e nele empupa. É a lagarta exofítica 
mais abundante associada a $B$. serice $a$, ocorrendo o ano inteiro e apresentando dois picos de abundância, um maior nos meses de junho e agosto e outro menor em fevereiro. Esta espécie foi encontrada também em B. crassa no cerrado (Diniz \& Morais 1995).

\section{Inga inflammata (Lepidoptera: Oecophoridae)}

Esta lagarta ocorre normalmente em um emaranhado de folhas secas, formado naturalmente ou feito, muitas vezes, por $G$. indecora. Alimenta-se sempre de folhas próximas ao emaranhado e, quando perturbada, se lança ao chão com movimentos bruscos. Antes de empupar, recorta um círculo na folha e, utilizando seda, junta as laterais, formando um envelope, dentro do qual empupa (Fig. 3G). Este casulo provavelmente cai ao chão, a não ser que se encontre no emaranhado de folhas de G. indecora, onde pode permanecer abrigado. Ocorre ao longo de todo ano, mas apresenta um pico de abundância em junho.

\section{Kolana ergina (Lepidoptera: Lycaenidae)}

De coloração amarelo avermelhada, a lagarta possui vários prolongamentos na forma de espinhos no corpo (Fig. 3H). Foi encontrado apenas um indivíduo ao longo do ano, no mês de outubro. Essa espécie, antes pertencente ao gênero Thecla, já foi registrada no cerrado alimentando-se de outras famílias além de Malpighiaceae, como Melastomataceae e Connaraceae (Diniz \& Morais 2002).

\section{Megalopyge lanata (Lepidoptera: Megalopygidae)}

As lagartas desta família são conhecidas vulgarmente como lagartas de fogo ou taturanas porque possuem longos pêlos urticantes, que podem causar graves lesões ao homem (Beard 1963). O corpo é amarelado com listras pretas e os pêlos são vermelhos na base e pretos no ápice (Fig. 3J). Podem chegar a cinco centímetros de comprimento e o casulo da pupa é feito com seda e os próprios pêlos. Foi encontrado apenas um indivíduo durante o mês de dezembro. São polífagas, alimentando-se de folhas em diferentes famílias de plantas, como Malpighiaceae, Guttiferae (Diniz \& Morais 1995) e Myrtaceae (Molina et al. 2002).

\section{Oiketicus kirbyi (Lepidoptera: Psychidae)}

Diferentemente de Lumacra sp. (Fig. 3I), outro Psychidae associado a $B$. sericea, que utiliza pedaços de folhas para a construção de seu abrigo, a lagarta de Oiketicus kirbyi (Fig. $3 \mathrm{~K}$ ) constrói seu casulo com seda e pequenos gravetos. Os Psychidae empupam dentro de seu casulo e normalmente apenas os machos emergem como adultos completamente desenvolvidos (Borror \& DeLong 1969). Oiketicus kirbyi ocorreu o ano inteiro em baixa abundância. É uma espécie polífaga que se alimenta externamente de folhas de várias famílias de plantas: Malpighiaceae, Rutaceae, Erythroxylaceae, Vochysiaceae (Diniz \& Morais 1997, 1995), Myrtaceae (Pereira et al. 2001), Musaceae (Stephens 1962; Ramírez et al. 1999) e Aquifoliaceae (Iede \& Machado 1989).

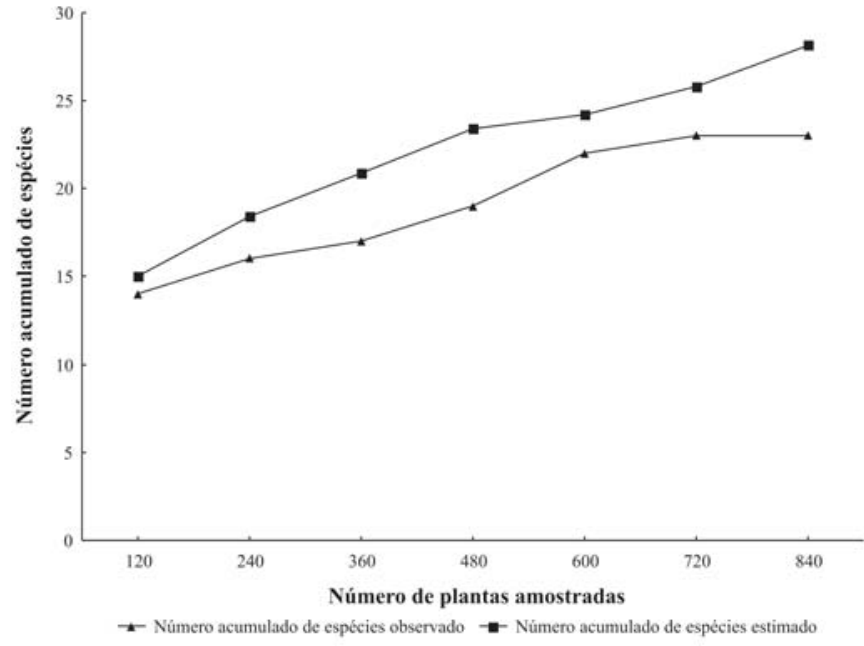

Fig. 4. Curvas de acumulação de espécies observada e estimada (Estimador de Jack-Knife 1) de insetos fitófagos em relação ao número de plantas de Byrsonima sericea vistoriadas no Parque Nacional da Restinga de Jurubatiba.

\section{Phobetron hipparchia (Lepidoptera: Limacodidae)}

Suas lagartas possuem apêndices carnosos laterais, que se destacam com facilidade e não servem para a locomoção (Lima 1955). Apresenta coloração marrom e pêlos curtos que recobrem todo o corpo. O casulo da pupa é construído com seus próprios pêlos e seda. Foi encontrado apenas um único indivíduo no período de observações preliminares (antes de 2003). Alimenta-se de folhas em B. sericea e é uma espécie polífaga, havendo registros de sua ocorrência em Rutaceae (Galvan et al. 2002), Erythroxylaceae, Malpighiaceae (Diniz e Morais 1995), Anacardiaceae, (Diniz e Morais 1995; VanBael et al. 2004), Moraceae (Van Bael et al. 2004), Myrtaceae (Pereira et al. 2001) e Musaceae (Ramírez et al. 1999).

\section{Rhipha strigosa (Lepidoptera: Arctiidae)}

A lagarta, de coloração amarela e com uma mancha azulada na parte anterior, é coberta por numerosos e densos pêlos ao longo de todo corpo e possui longos tufos de pêlos brancos na parte anterior e um na parte posterior do corpo (Fig. 3L). Alimenta-se de folhas e constrói o casulo pupal com seus próprios pêlos e seda. Foi encontrado apenas um único indivíduo durante o período de observações preliminares.

\section{Stenoma prope ascodes (Lepidoptera: Elachistidae)}

De coloração marrom, a lagarta deste microlepidóptero, apresenta o corpo achatado dorso-ventralmente e abriga-se entre duas folhas verdes, que une com seda. Quando perturbada, joga-se ao chão com movimentos rápidos e bruscos. Apresentou uma distribuição esparsa e foi pouco abundante ao longo do ano.

\section{Coleoptera exofíticos}

Chlamisus spp. (Coleoptera: Chrysomelidae)

Foram encontradas quatro espécies de Chlamisus 
associadas a B. sericea. As larvas de Chlamisinae, da mesma forma que as larvas de muitas subfamílias de Chrysomelidae, constroem um casulo de fezes, que carregam durante todo o seu desenvolvimento e onde empupam. Os casulos das espécies encontradas são todos na forma de cones, e podem apresentar, além das fezes, também tricomas do caule e das folhas da planta hospedeira (Fig. 3M). Os indivíduos dessas espécies podem se alimentar raspando a nervura de folhas ou de caules jovens. As espécies de Chlamisus foram encontradas durante o ano inteiro, mas foi observado um pico de abundância em agosto. Já foram registradas espécies de Chlamisus em espécies do gênero Byrsonima no cerrado (Diniz 2000) e em B. crassifolia na Costa Rica (Guadamuz et al. 1998).

\section{Fulcidax monstrosa (Coleoptera: Chrysomelidae)}

A fêmea coloca um único ovo de cada vez em ramos jovens da planta hospedeira e o cobre com suas fezes, construindo um escudo de excrementos. A larva eclodida permanece nele, adicionando mais camadas de suas próprias fezes ao seu casulo à medida que cresce (Fig. 3N). Após no máximo quatro meses, a larva empupa no casulo, que permanece fechado por mais quatro meses até a emergência do adulto. Sua estação reprodutiva inicia-se entre junho e julho, o pico de ovos é em novembro, o de larvas em dezembro e o de pupas, em abril. Fatores climáticos assim como disponibilidade de recurso foram sugeridos para explicar a sazonalidade da espécie (Flinte $\&$ Macedo 2004). Larvas e adultos raspam o caule de sua única planta hospedeira na área de estudo, $B$. sericea (Malpighiaceae), removendo os tecidos superficiais e o floema. A retirada completa destes tecidos, que ocorre quando o inseto raspa o caule em toda sua circunferência, acarreta na morte do ramo do ponto atacado até o seu ápice (Flinte \& Macedo 2003).

\section{Naupactus lar (Coleoptera: Curculionidae)}

Os adultos (Fig. 3O) do gênero Naupactus alimentam-se de folhas e as larvas são brocadoras de raiz, podendo causar graves prejuízos à agricultura (e.g. Ribeiro 2000; Lanteri et al. 200). Foram encontrados adultos de $N$. lar em grande número em $B$. sericea entre os meses de outubro e fevereiro, possivelmente sua época reprodutiva.

\section{Minadores}

\section{Lius sp. (Coleoptera: Buprestidae)}

A larva dessa espécie produz uma mina expandida nas folhas (Fig. 3Q), e o adulto deixa a câmara pupal através de um pequeno orifício na parte inferior da folha. Os adultos são mais alongados que Pachyschelus sp. e possuem coloração vinho escuro. Trata-se da espécie mais abundante associada a $B$. sericea, ocorrendo o ano inteiro, mas com um pico no período de maio e junho.

Pachyschelus sp. (Coleoptera: Buprestidae)

A larva deste minador produz uma mina linear nas folhas e,

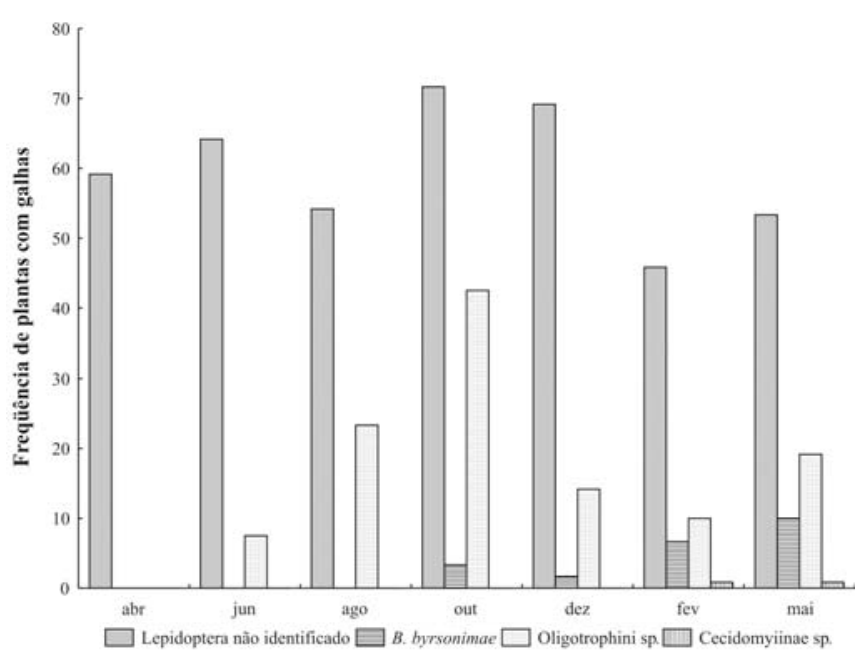

Fig. 5. Frequiência (\%) de plantas com cada espécie galhadora durante o período de estudo.

ao final do canal de alimentação, encontra-se a câmara pupal, que possui forma arredondada (Fig. 3R). Para emergir, o adulto abre um orifício na câmara, na parte superior da folha. Os adultos possuem corpo em forma de gota e coloração azul escuro. Ocorre durante todo o ano, com as maiores abundâncias registradas em junho e agosto.

\section{Galhadores}

\section{Bruggmaniella byrsonimae (Diptera: Cecidomyiidae)}

Este cecidomiídeo induz uma galha no botão floral de $B$. sericea (Maia 2001a, 2001b) e, comumente, são encontradas inflorescências com praticamente todos os botões galhados (Fig. 3U). O botão galhado fica com um aspecto murcho e apresenta coloração marrom. Esta galha foi encontrada de outubro a maio.

\section{Distribuição temporal dos insetos fitófagos e a fenologia de Byrsonima sericea}

O acompanhamento da frequiência de plantas galhadas ao longo do ano mostra que a galha de Lepidoptera é comum durante todo o ano, porém a maior freqüência de plantas com este tipo de galha ocorre entre os meses de outubro e dezembro. Em contraste, a freqüência de plantas com as demais galhas variou consideravelmente durante o ano, sendo que é mais alta em outubro, para Oligotrophini sp. e em maio, para Bruggmaniella byrsonimae, enquanto que Cecidomyiinae sp. ocorreu entre fevereiro e maio, mas com uma freqüência muito baixa (Fig. 5). De uma maneira geral, os meses de outubro e dezembro apresentaram as maiores freqüências de plantas atacadas pelos galhadores.

O número de indivíduos de lagartas exofíticas exibiu um pico entre os meses de junho e agosto, basicamente determinado pela abundância de G. indecora, precedendo, portanto, à maior produção de folhas novas, que vai de 
outubro a dezembro (Fig. 6). De forma semelhante às lagartas, os minadores apresentaram seu pico de abundância em junho, antes do aumento da produção de folhas novas (Fig. 6), influenciado principalmente pela abundância de Lius sp. Já em relação aos imaturos de besouros exofíticos, que estão preponderantemente representados por $F$. monstrosa, verificou-se que o aumento do número de indivíduos acompanha o aumento da freqüência de plantas com folhas novas e, da mesma forma, ocorre a diminuição da abundância do besouro depois da queda da produção de folhas novas (Fig. 6). Estes besouros alimentem-se dos caules jovens de $B$. sericea (Flinte et al. 2003), cuja disponibilidade depende do período de crescimento vegetativo da planta, da mesma forma que as folhas novas.

Apesar dos padrões de abundância descritos (Fig. 6) serem regidos pelo número de indivíduos das espécies dominantes, foi verificado que a maior parte das demais espécies menos abundantes seguiu o mesmo padrão. Além de G. indecora, as três espécies de lagartas mais abundantes, E. divisa, G. exquisita e I. inflammata e o minador Pachyschelus sp. apresentaram seus picos de abundância em junho. Assim, o padrão de ocorrência de lagartas e de minadores parece ser similar entre todas as espécies mais abundantes destes dois grupos.

O fato das lagartas exofíticas e dos minadores apresentarem pico de abundância em uma época aparentemente desfavorável tanto por condições climáticas (período mais seco, Fig. 2) quanto por disponibilidade de recurso (poucas folhas novas, Fig. 6) foi inesperado, já que o padrão de sazonalidade de insetos tropicais tem sido muitas vezes correlacionado com a precipitação, com os picos de abundância ocorrendo na estação chuvosa (Wolda 1980, 1988). Embora o inverno na restinga seja normalmente o período de menor precipitação do ano, eventualmente pode haver pouca diferença em relação às demais estações. A redução da temperatura e a conseqüiente menor taxa de evaporação no inverno pode produzir um balanço hídrico mais próximo entre as diferentes estações. Além disso, a umidade na restinga durante a noite pode chegar a valores muito altos, mesmo nos meses mais secos (obs. pess.), podendo, assim, suprir a necessidade de água dos organismos. Desta forma, é possível que as condições climáticas aparentemente desfavoráveis no outono e, principalmente, no inverno, não sejam tão restritivas à reprodução dos insetos fitófagos.

Entre os fatores bióticos que devem influenciar a abundância de insetos tropicais no tempo estão a disponibilidade e a qualidade dos recursos da planta hospedeira, além dos inimigos naturais. O período de brotamento de folhas novas inicia-se em julho, posteriormente ao pico de abundância de lagartas e minadores (que ocorre principalmente em junho) e estende-se até março, no final do verão, sendo que a maior frequiência de plantas com folhas novas ocorre entre os meses de outubro e dezembro (veja descrição detalhada em Flinte \& Macedo 2004). É durante estes meses que mais de $50 \%$ das plantas apresentam pelo menos metade de suas folhas em estado jovem (Fig. 6). Desta forma,

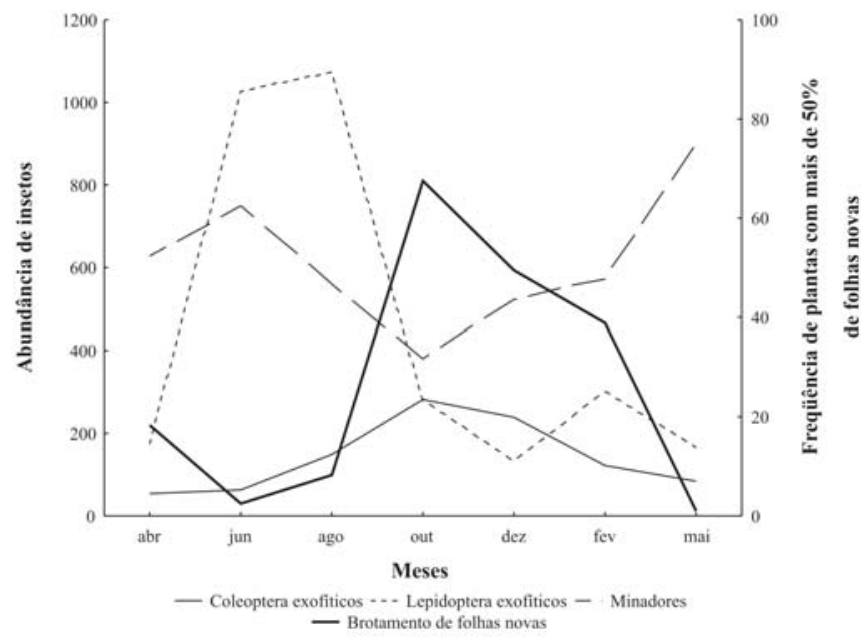

Fig. 6. Abundância de minadores e de imaturos exofíticos de lepidópteros e de besouros em relação à freqüência $(\%)$ de plantas com mais de $50 \%$ de suas folhas em estado jovem.

não é esperada a maior abundância de insetos no outono ou inverno, em uma época de disponibilidade de recursos baixa, quando poucas plantas estão na fase de brotamento de folhas novas. Porém, verificou-se que tanto as lagartas de lepidópteros $\left(\mathrm{X}^{2}=290,98 ; \mathrm{df}=3 ; \mathrm{p}<0,00000\right)$, como os minadores $\left(X^{2}=394,21 ; d f=3 ; p<0,00000\right)$, concentram significativamente seus indivíduos justamente nestas poucas plantas com folhas novas durante esta época aparentemente desfavorável. Assim, a quantidade baixa de recursos disponíveis no inverno não impede que nessa época ocorra maior abundância dos insetos e, além disso, muitas espécies devem estar utilizando, em menor ou maior grau, também folhas maduras para a sua alimentação.

Morais e colaboradores (1999), em um trabalho sobre lagartas exofíticas em nove espécies de plantas hospedeiras (incluindo três espécies de Byrsonima), encontraram também um aumento na frequiência de plantas com lagartas no início da estação seca no cerrado, precedendo o pico de brotamento de folhas novas, que ocorre no início da estação chuvosa. Os autores sugerem que a baixa densidade de lagartas no início da estação chuvosa poderia ser explicada pelas defesas presentes nas folhas, atraso na emergência de adultos ou ainda uma alta proporção de predadores e parasitóides. Eles observaram que a porcentagem de lagartas das quais emergiram parasitóides foi cerca de sete vezes maior em outubro, no início da estação chuvosa, quando é mais baixa a abundância de lagartas, do que em junho, mês de maior proporção de plantas com lagartas. Assim, o padrão observado no cerrado poderia ser explicado por um escape de inimigos naturais. Para a restinga não há dados suficientes sobre parasitismo para avaliar se o padrão observado pode ser atribuído à pressão de inimigos naturais, como predadores e parasitóides.

Pode-se concluir no presente trabalho que a escolha de plantas representativas, com ampla distribuição geográfica, parece promissora para o estudo comparativo da entomofauna associada, uma vez que fornece subsídios para definir padrões 
temporais e avaliar a importância de fatores ambientais sobre a comunidade de insetos fitófagos. Este trabalho mostra que a riqueza de espécies de lagartas de Lepidoptera associadas a $B$. sericea na restinga é próxima à encontrada em outras espécies de Byrsonima no cerrado, apesar da similaridade na composição de espécies de lagartas ser baixa. A comparação com os resultados obtidos para Byrsonima no cerrado também revelou um padrão de distribuição temporal de lagartas muito semelhante à restinga. Percebe-se assim, a necessidade de mais estudos comparativos para uma avaliação adequada sobre o grau de riqueza e similaridade entre diferentes ambientes. Isto contribuiria não apenas para o conhecimento do hábito alimentar e da composição de espécies de insetos fitófagos em uma planta, mas também para um entendimento mais aprofundado das interações inseto-planta e na compreensão da estrutura e da evolução de comunidades de insetos tropicais.

Agradecimentos. Somos gratos pelas indentificações de: Curculionidae pelo Dr. Sérgio Vanin (Depto. de Zoologia/USP); Hispinae pelo Dr. Charles Staines (Smithsonian NMNH); Buprestidae pelo Dr. Henry Hespenheide (Dept. of Organismic Biology, Ecology and Evolution/UCLA); Lycaenidae pelo Dr. Robert K. Robbins (Smithsonian NMNH); Chlamisinae pelo Dr. Jay Karren (Utah State University); lepidópteros pelo Dr. Vitor Becker. Gostaríamos também de agradecer ao Programa de Pós-Graduação em Ecologia (UFRJ), à CAPES pela bolsa de mestrado (VF), ao CNPq (bolsa de produtividade RFM) e CNPq/PELD (Pesquisas Ecológicas de Longa Duração) pelo financiamento, ao IBAMA/PNRJ pelo suporte em campo, e à equipe do Laboratório de Ecologia de Insetos (UFRJ).

\section{REFERÊNCIAS}

Araujo, D. S. D.; F. R. Scarano; C. F. C. Sá; B. C. Kurtz; H. L. T. Zaluar; R. C. M. Montezuma \& R. C. Oliveira. 1998. Comunidades vegetais do Parque Nacional da Restinga de Jurubatiba, p. 39-62. In: F. A. Esteves (ed.). Ecologia das Lagoas costeiras do Parque Nacional da Restinga de Jurubatiba e do Município de Macaé (RJ). Rio de Janeiro, NUPEM-UFRJ, 442 p.

Araujo, D. S. D.; A. F. Costa; A. S. Oliveira \& R. L. Moura. 2001. Florística e padrões fitogeográficos, p. 155-165. In: A. Costa \& I. C. A. Dias (orgs.). Flora do Parque Nacional da Restinga de Jurubatiba e arredores, Rio de Janeiro, Brasil: listagem florística e fitogeografia. Rio de Janeiro, Museu Nacional/UFRJ, $200 \mathrm{p}$.

Battirola, L. D.; M. I. Marques; J. Adis \& J. H. Delabie. C. 2005. Composição da comunidade de Formicidae (Insecta, Hymenoptera) em copas de Attalea phalerata Mart. (Arecaceae) no Pantanal de Poconé, Mato Grosso, Brasil. Revista Brasileira de Entomologia 49: $107-117$.

Beard-, R. L. 1963. Insect Toxins and Venoms. Annual Review of Entomology 8: 1-18.

Borror, D. J. \& D.M. DeLong. 1969. Introdução ao Estudo dos Insetos. São Paulo, Editora Edgard Blücher Ltda, 653 p.

Cisneros, F. H. 1995. Control de Plagas Agrícolas. Lima, Universidad Nacional Agraria La Molina, 304 p.

Diniz, I. R. \& H. C. Morais. 1995. Larvas de Lepidoptera e suas plantas hospedeiras em um cerrado de Brasília, DF, Brasil. Revista Brasileira de Entomologia 39: 755-770.

Diniz, I. R. \& H. C. Morais. 1997. Lepidopteran caterpillar fauna of cerrado host plants. Biodiversity and Conservation 6: $817-$ 836.

Diniz, I. R.; H. C. Morais \& J. D. Hay. 2000. Natural history of herbivores feeding on Byrsonima species. Brazilian Journal of Ecology 1 \& 2: 49-54.

Esteves, F. A. (ed.) 1998. Ecologia das Lagoas costeiras do Parque Nacional da Restinga de Jurubatiba e do Município de Macaé (RJ). Rio de Janeiro, NUPEM-UFRJ, 442 p.

Esteves, F. A. \& L. D. Lacerda. (eds.). 2000. Ecologia de Restingas e Lagoas Costeiras. Rio de Janeiro, NUPEM-UFRJ, xii+394 p.

Ferraz, F. F. F. \& R. F. Monteiro. 2003. Complex interactions envolving a gall midge Myrciamyia maricaensis Maia (Diptera, Cecidomyiidae), phytophagous modifiers and parasitoids. Revista brasileira de Zoologia 20: 433-437.

Flinte, V.; M. V. Macedo; R. C. Vieira \& J. B. Karren. 2003. Feeding behavior of Fulcidax monstrosa (Chlamisinae) on its host plant Byrsonima sericea (Malpighiaceae), p. 155-159. In: D. G. Furth (ed.). Special Topics in Leaf Beetle Biology. Proceedings of the Fifth International Symposium on the Chrysomelidae. Sofia-Moscow, Pensoft Publishers, xii+339 p.

Flinte, V. \& M. V. Macedo. 2004. Population ecology of Fulcidax monstrosa (Chlamisinae), p. 623-631. In: P. H. Jolivet; J. A. Santiago-Blay \& M. Schmitt (eds.). New developments in the Biology of Chrysomelidae. The Hague, SPB Academic Publishing, $\mathrm{xx}+803 \mathrm{p}$.

Galvan, T. L.; M. C. Picanço; L. Bacci; E. J. G. Pereira \& A. L. B. Crespo. 2002. Seletividade de oito inseticidas a predadores de lagartas em citros. Pesquisa Agropecuária brasileira 37: 117 122.

Gonçalves, R. O. \& M. V. Macedo. 2003. Population ecology of the polymorphic species Chelymorpha cribraria (Col.: Chrysomelidae) in Rio de Janeiro, Brazil, p. 285-294. In: D. G. Furth (ed.). Special Topics in Leaf Beetle Biology. Proceedings of the Fifth International Symposium on the Chrysomelidae. SofiaMoscow, Pensoft Publishers, xii+339 p.

Grenha, V.; M. V. Macedo \& R. F. Monteiro. 2004. Geographical variation in Mecistomela marginata (Hispinae), p. 225-230. In: P. H. Jolivet; J. A. Santiago-Blay \& M. Schmitt (eds.). New developments in the Biology of Chrysomelidae. The Hague, SPB Academic Publishing, $x x+803 \mathrm{p}$.

Guadamuz, A.; A. Masís; R. Espinoza; D. Perez \& F. Chavarria. 1998. Species page de Byrsonima crassifolia (Malpighiaceae), 8 setiembre 1998. Species Home Pages, Área de Conservación Guanacaste, Costa Rica. Disponível em: http:// www.acguanacaste.ac.cr. [acessado em 08 de outubro de 2005].

Iede, E. T. \& D. C. Machado. 1989. Pragas da erva-mate (Ilex paraguariensis St Hill.) e seu controle. Boletim de Pesquisa Florestal 18/19: 51-60.

Jones, M. T.; I. Castellanos \& M. R. Weiss. 2002. Do leaf shelters always protect caterpillars from invertebrate predators? Ecological Entomology 27: 753-757.

Jolivet, P. 1997. Biologie des Coléoptères Chrysomélides. Paris, Société Nouvelle des Éditions Boubée, 279 p.

Krebs, C. J. 1989. Ecological Methodology. New York, Harper Collins Publishers, $654 \mathrm{p}$.

Lanteri, A. A.; J. C. Guedes \& J. R. P. Parra. 2002. Weevils Injurious for Roots of Citrus in São Paulo State, Brazil. Neotropical Entomology 31: 561-569.

Lewinsohn, T. M.; P. I. K. L. Prado \& A. M. Almeida. 2001. Inventários bióticos centrados em recursos: Insetos fitófagos e plantas hospedeiras, p. 174-189. In: I. Garay \& B. Dias (orgs.). Conservação da Biodiversidade em Ecossistemas Tropicais. Petrópolis, Editora Vozes, 430 p.

Lima, A. C. 1945. Insetos do Brasil. 5o Tomo. Lepidópteros. 1 Parte. Rio de Janeiro, Serviço Gráfico do I.B.G.E., 379 p.

Macedo, M. V.; R. F. Monteiro \& T. M. Lewinsohn. 1994. Biology and ecology of Mecistomela marginata (Thunberg, 1821) (Hispinae: Alurnini) in Brazil, p. 567-571. In: P. H. Jolivet; M. Cox \& E. Petitpierre (eds.). Novel Aspects of the Biology of Chrysomelidae. Dordrecht, Kluwer Academic Publishers, xvi + $582 \mathrm{p}$.

Macedo, M. V.; V. Grenha; V. Flinte \& T. S. Rabello. 2004. Besouros 
fitófagos da Restinga de Jurubatiba, p. 117-126. In: C. F. D. Rocha; F. A. Esteves \& F. R. Scarano (orgs.). Pesquisas de Longa Duração na Restinga de Jurubatiba. Ecologia, História Natural e Conservação. São Carlos, RiMa Editora, 374 p.

Madeira, J. A.; V. C. Maia \& R. F. Monteiro. 2002. Gall makers (Cecidomyiidae, Diptera) on Calophyllum brasiliense Camb. (Clusiaceae): descriptions and biology. Arquivos do Museu Nacional, RJ, 61: 31-48.

Maia, V. C. 2001a. New genera and species of gall midges (Diptera, Cecidomyiidae) from three restingas of Rio de Janeiro State, Brazil. Revista brasileira de Zoologia 18: 1-32.

Maia, V. C. 2001b. The gall midges (Diptera: Cecidomyiidae) from three restingas of Rio de Janeiro State, Brazil. Revista brasileira de Zoologia 18: 583-629.

Marquis, R. J.; H. C. Morais \& I. R. Diniz. 2002. Interactions among cerrado plants and their herbivores: unique or typical? p. 306-328. In: P. S. Oliveira \& R. J. Marquis (eds.). The cerrados of Brazil: ecology and natural history of a Neotropical savanna. New York, Columbia University Press, $398 \mathrm{p}$.

Molina, J. C.; P. G. Pereira \& M. Q. Gonzalez. 2002. Insectos y Ácaros del guayabo (Psidium guajava L.) en plantaciones comerciales del estado Zulia, Venezuela. Revista de la Facultad de Agronom 19: 140-148.

Monteiro, R. F. \& M. V. Macedo. 2000. Flutuação populacional de insetos fitófagos em restinga, p. 77-88. In: F. A. Esteves \& L. D. Lacerda (eds.). Ecologia de Restingas e Lagoas Costeiras. Rio de Janeiro, NUPEM/UFRJ, xii+394 p.

Monteiro, R. F. \& V. O. Becker. 2002. A new Sigelgaita Heinrich (Lepidoptera, Pyralidae, Phycitinae) feeding on cacti in Brazil. Revista brasileira de Zoologia 19: 299-304.

Monteiro, R. F.; R. A. M. Oda; K. L. Narahara \& P. A. L. Constantino. 2004a. Galhas: diversidade, especificidade e distribuição, p. $127-$ 142. In: C. F. D. Rocha; F. A. Esteves \& F. R. Scarano (orgs.). Pesquisas de Longa Duração na Restinga de Jurubatiba. Ecologia, História Natural e Conservação. São Carlos, RiMa Editora, $374 \mathrm{p}$

Monteiro, R. F.; A. P. Esperanço; V. O. Becker; L. S. Otero; E. V. Herkenhoff \& A. Soares. 2004b. Mariposas e borboletas na Restinga de Jurubatiba, p. 143-164. In: C. F. D. Rocha; F. A. Esteves \& F. R. Scarano (orgs.). Pesquisas de Longa Duração na Restinga de Jurubatiba. Ecologia, História Natural e Conservação. São Carlos, RiMa Editora, 374 p.

Morais, H. C.; I. R. Diniz \& D. M. S. Silva. 1999. Caterpillar seasonality in a central Brazilian cerrado. Revista de Biologia Tropical 47: $1025-1033$.

Nielsen, V.; P. Hurtado \& D. H. Janzen. 2004. Recolecta de artrópodos para prospección de la biodiversidad en el Área de Conservación Guanacaste, Costa Rica. Revista de Biología Tropical 52: 119_ 132.
Nogueira-de-Sá, F. \& J. R. Trigo. 2002. Do fecal shields provide physical protection to larvae of the tortoise beetles Plagiometriona flavescens and Stolas chalybea against natural enemies? Entomologia Experimentalis et Applicata 104: 203-206.

Pereira, E. 1952. Contribuição ao conhecimento da Família Malpighiaceae. Arquivo do Serviço Florestal. Vol. 7. Rio de Janeiro, Ministério da Agricultura, $70 \mathrm{p}$

Pereira, J. M. M.; V. Zanuncio \& T. J. C. Zanuncio. 2001. Lepidoptera pests collected in Eucalyptus urophylla (Myrtaceae) plantations during five years in Três Marias, State of Minas Gerais, Brazil. Revista de Biología Tropical 49: 1073-1082.

Price, P. W.; I. R. Diniz; H. C. Morais \& E. S. A. Marques. 1995. The abundance of insect herbivore species in the tropics: the high local richness of rare species. Biotropica 27: 468-478.

Ramírez, R.; O. Domínguez; O. Liscano; M. Vilchez \& R. Urdaneta. 1999. Importancia de Antichloris viridis Druce como lepidóptero defoliador del plátano (Musa AAB cv. Hartón) en la zona sur del Lago de Maracaibo, Venezuela. Revista de la Facultad de Agronom 16: 88-94.

Ribeiro, A. 2000. Proyecto difusión de la EEMAC: construyendo propuestas colectivas. Revista de la Estacion Experimental "Dr. Mario A. Cassinoni" 19: 22-25.

Rocha, C. F.; F. A. Esteves \& F. R. Scarano. (orgs.). 2004. Pesquisas de longa duração na Restinga de Jurubatiba. Ecologia, História Natural e Conservação. São Carlos, RiMa Editora, $374 \mathrm{p}$.

Silva, A. G. A.; C. R. Gonçalves; D. M. Galvão; A. J. L. Gonçalves; J. Gomes; M. N. Silva \& L. Simoni. 1968. Quarto Catálogo dos Insetos que Vivem nas Plantas do Brasil. Seus Parasitos e Predadores. Parte II - 1⿳o Tomo. Rio de Janeiro, Ministério da Agricultura, $622 \mathrm{p}$.

Stephens, C. S. 1962. Oiketicus kirbyi (Lepidoptera : Psychidae): A pest of Bananas in Costa Rica. Journal of Economic Entomology 55

Van Bael, S. A.; A. Aiello; A. Valderrama; E. Medianero; M. Samaniego \& S. J. Wright. 2004. General herbivore outbreak following an El Ni no-related drought in a lowland Panamanian forest. Journal of Tropical Ecology 20: 625-633.

Wallace, J. B. 1970. The defensive function of a case on a chrysomelid larva. Journal of the Georgia Entomological Society 5: 1924.

Wolda, H. 1980. Seasonality of tropical insects. I. Leafhoppers (Homoptera) in Las Cumbres, Panama. Journal of Animal Ecology 49: 277-290.

Wolda, H. 1988. Insect seasonality: why? Annual Review of Ecology and Systematics 19: 1-18. 